\title{
Protein profiling of 3T3-L1 adipocyte differentiation and (tumor necrosis factor alpha-mediated) starvation
}

Citation for published version (APA):

Renes, J., Bouwman, F. G., Noben, J. P., Evelo, C. T., Robben, J., \& Mariman, E. (2005). Protein profiling of 3T3-L1 adipocyte differentiation and (tumor necrosis factor alpha-mediated) starvation. Cellular and Molecular Life Sciences, 62(4), 492-503. https://doi.org/10.1007/s00018-004-4498-9

Document status and date:

Published: 01/01/2005

DOI:

10.1007/s00018-004-4498-9

Document Version:

Publisher's PDF, also known as Version of record

Document license:

Taverne

Please check the document version of this publication:

- A submitted manuscript is the version of the article upon submission and before peer-review. There can be important differences between the submitted version and the official published version of record.

People interested in the research are advised to contact the author for the final version of the publication, or visit the DOI to the publisher's website.

- The final author version and the galley proof are versions of the publication after peer review.

- The final published version features the final layout of the paper including the volume, issue and page numbers.

Link to publication

\footnotetext{
General rights rights.

- You may freely distribute the URL identifying the publication in the public portal. please follow below link for the End User Agreement:

www.umlib.nl/taverne-license

Take down policy

If you believe that this document breaches copyright please contact us at:

repository@maastrichtuniversity.nl

providing details and we will investigate your claim.
}

Copyright and moral rights for the publications made accessible in the public portal are retained by the authors and/or other copyright owners and it is a condition of accessing publications that users recognise and abide by the legal requirements associated with these

- Users may download and print one copy of any publication from the public portal for the purpose of private study or research.

- You may not further distribute the material or use it for any profit-making activity or commercial gain

If the publication is distributed under the terms of Article $25 \mathrm{fa}$ of the Dutch Copyright Act, indicated by the "Taverne" license above, 


\title{
Research Article
}

\section{Protein profiling of 3T3-L1 adipocyte differentiation and (tumor necrosis factor $\alpha$-mediated) starvation}

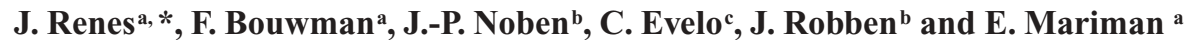 \\ a Maastricht Proteomics Center, Nutrition and Toxicology Research Institute Maastricht (NUTRIM), \\ Department of Human Biology, Maastricht University, P.O. Box 616, 6200 MD Maastricht (The Netherlands), \\ Fax: +31 (0)43 3670976, e-mail: j.renes@hb.unimaas.nl \\ b Biomedical Research Institute, Limburgs Universitair Centrum and School of Life Sciences, \\ Transnational University Limburg, 3590 Diepenbeek (Belgium) \\ ${ }^{\mathrm{c}}$ BiGCaT Bioinformatics, Technical University Eindhoven and Maastricht University, P.O. Box 616, 6200 MD \\ Maastricht (The Netherlands)
}

Received 9 November 2004; received after revision 21 December 2004; accepted 28 December 2004

\begin{abstract}
The increased incidence of obesity and related disorders in Western societies requires a thorough understanding of the adipogenic process. Data at the protein level of this process are scarce. Therefore we performed a proteome analysis of differentiating and starving 3T3L1 cells using two-dimensional gel electrophoresis combined with mass spectrometry. Effects of different starvation conditions were examined by subjecting 3T3-L1 adipocytes to caloric restriction, either in the absence or the presence of the lipolysis inducer tumor necrosis factor- $\alpha$. Ninety-three differentially expressed proteins were
\end{abstract}

found during differentiation and starvation of 3T3-L1 cells, 50 of which were identified. GenMAPP/MAPPfinder software revealed a non-reciprocal regulation of the glycolytic pathway during 3T3-L1 differentiation followed by starvation. Furthermore, proteins involved in growth regulation, cytoskeletal rearrangements and protein modification, 16 of which have not been described before in 3T3-L1 cells, were identified. In conclusion, our data provide valuable information for further understanding of the adipogenic process.

Key words. 3T3-L1; proteomics; differentiation; caloric restriction; TNF- $\alpha$.

In Western societies, obesity is taking on epidemic proportions, which will lead to an increased population risk for obesity-related complications such as type II diabetes and cardiovascular diseases [1]. Treatment and, more importantly, prevention of obesity are necessary to reduce the risk for these disorders. Hence, targets for future intervention are required, which necessitates a thorough understanding of the development of obesity.

Obesity is the result of a chronic imbalance between energy intake and energy expenditure that leads to an in-

\footnotetext{
* Corresponding author.
}

crease in fat cell size and number [2, 3]. Several studies with transciptomics data from in vitro and in vivo experiments on obesity-related model systems have already provided insight into gene regulation during adipogenesis [4-7]. This facilitates further detailed studies to dissect molecular pathways involved in obesity.

Although the power of the DNA array is highly appreciated, the predictive value of mRNA expression is limited with respect to cellular physiology. Expression levels of mRNA often do not parallel the levels of protein expression from a particular gene $[8,9]$ and protein turnover and post-translational modifications, essential for cellular behavior, are not covered by the information obtained from 
DNA arrays [10]. Consequently, a broader understanding of the adipogenic process requires independent examination of protein expression and protein function complementing the mRNA expression analyses.

We used a combined two-dimensional (2D) electrophoresis/mass spectrometry approach to further understand the molecular mechanisms involved in fat storage and fat depletion in mouse 3T3-L1 cells which serve as a wellknown model system for adipogenesis. Thus far, only a limited number of reports have described profiling of cellular proteins with a focus on 3T3-L1 differentiation [11-14], with Welsh et al. [13] and Choi et al. [14] using similar techniques as ours. Moreover, in addition to 3T3L1 differentiation, we also investigated differences in the proteome during starvation of 3T3-L1 adipocytes, because understanding of the conversion of adipocytes to a fat-depleted status may further contribute to knowledge about the response of adipose cells to different nutritional conditions. The response of mature 3T3-L1 adipocytes to starvation was examined by caloric restriction in either the absence or the presence of the lipolysis inducer tumor necrosis factor- $\alpha$ (TNF- $\alpha)[15,16]$. The aim of this study was to obtain a more comprehensive view of fat cell differentiation and starvation. This may possibly result in potential targets for improved future intervention strategies with respect to obesity and obesity-related disorders.

\section{Materials and methods}

Chemicals were purchased from Sigma (Zwijndrecht, The Netherlands) unless stated otherwise.

\section{Cell culture and cellular Oil Red $O$ accumulation}

Mouse 3T3-L1 fibroblasts were purchased from the American Type Culture Collection and were differentiated into adipocytes as described elsewhere [17], only with 18 days of differentiation. Differentiation was monitored by the visual appearance of fat droplets in the cells. Subsequently, adipocytes were subjected to a starvation period of 4 days by culturing them in DMEM (Invitrogen, Breda, The Netherlands) without glucose and insulin containing $4 \%$ fetal calf serum either in the absence or the presence of $1 \mathrm{nM}$ mouse TNF- $\alpha$.

At appropriate time points, cells were fixed with $3.7 \%$ formamide in DMEM/F12 (Invitrogen) for $10 \mathrm{~min}$ at room temperature. Cells were incubated with a filtered Oil Red O (ORO) solution ( $1 \%$ in isopropanol) for $30 \mathrm{~min}$ at room temperature. Cells were washed with $70 \%$ ethanol and dissolved in dimethylsulfoxide (DMSO) to determine the intracellular ORO content by spectrophotometry. The amount of intracellular ORO staining was corrected for the quantity of genomic DNA, since the number of living 3T3-L1 cells correlates with the amount of intact genomic DNA [18]. Images of the cells were taken with a Nikon TE 200 eclipse phase contrast microscope equipped with digital image acquisition.

\section{Protein sample preparation and 2D electrophoresis}

Protein sample preparation was performed as described previously [17]. Protein concentrations were determined by a Bradford-based protein assay (Bio-Rad, Veenendaal, The Netherlands). Protein concentrations were verified by densitometry with a GS-800 Calibrated Desitometer (Bio-Rad) of a silver-stained [19] SDS-PAGE gel that was used to control the protein sample contents. After correction according to the densitometry results, equal amounts of protein samples were subjected to 2D electrophoresis.

Separation of the protein samples by 2D electrophoresis was performed as described elsewhere $[17,20]$. For reproducible results, 12 gels were prepared, run and stained simultaneously. Gels were stained with silver according to Shevchenko et al. [19] with minor modifications using our in house-developed automated gel-staining machine. Gel images were taken by densitometrical scanning (GS800 Calibrated Densitometer; Bio-Rad) and gel images were further processed to determine differentially expressed proteins by image analysis software (PD-Quest 7.2, Bio-Rad) as described by Wang et al. [20]. To obtain more protein identities, preparative gels of the same samples were generated with fivefold more sample loads. These gels were stained with Coomassie Brilliant Blue $(\mathrm{CBB})$ and were further processed in a manner similar to the silver-stained gels. The CBB gels were matched with the silver-stained gels and spots earlier pinpointed as differentially expressed were excised from the CBB-stained gels and subjected to mass spectrometry.

\section{Protein identification}

Differentially expressed proteins were excised from the gels by an automated spot cutter (Bio-Rad) according to the manufacturer's instructions. Generation of tryptic digests from the proteins by in-gel digestion, Maldi-TOF analysis and subsequent database searching were performed as described previously [17].

Samples that could not be identified by Maldi-TOF were subjected to liquid chromatography tandem mass spectrometry (LC-MS/MS) [21]. Protein identification was performed by database searching as described elsewhere $[20,21]$.

\section{Data processing}

Differentially expressed proteins were categorized into seven clusters according to their expression pattern during the experimental conditions. Data from all clusters were analyzed using the GenMAPP-Mappfinder tandem of gene expression mapping software (version 2.0) (http://www.genmapp.org) [22, 23] in order to find relevant biological pathways. For this purpose, proteins were 
identified with their Swiss-Prot primary accession number and categorized in a single column using a positive numerical identifier for the experimental condition. The Mappfinder criterion was set to match all positive values (and thus all proteins present for any experimental condition). The dataset and criterion file were evaluated using Mappfinder [23] with both mapps derived from the Gene Ontology (http://www.geneontology.org) and mapps specifically build for GenMAPP (the so called local mapps), using the map set developed for mouse. A ranked list of mapps with higher numbers of changed proteins was created and mapps showing three or more changed proteins were considered relevant.

\section{Results}

\section{Intracellular ORO accumulation}

Intracellular fat contents during differentiation and starvation of 3T3-L1 cells were measured by ORO staining. Figure 1A shows that in 3T3-L1 pre-adipocytes, ORO staining of triglycerides was not observed (A). Differentiation of 3T3-L1 cells for 18 days resulted in an accumulation of triglycerides as shown by the red-colored cells (B). Starvation of these cells by caloric restriction without TNF- $\alpha$ reduced the amount of accumulated triglycerides (C); however, in the presence of TNF- $\alpha$ this reduction was stronger (D). These results were confirmed by measurement of the total amount of intracellular ORO, corrected for the number of living cells (fig. 1B). The content of intracellular ORO in differentiated 3T3-L1 adipocytes was strongly increased compared to preadipocytes and was set to $100 \%$. Caloric restriction of 3T3-L1 adipocytes in the absence of TNF- $\alpha$ reduced the intracellular ORO contents by $46 \%$, while in the presence of TNF- $\alpha$ this was reduced by $77 \%$.

\section{Protein profiling from 3T3-L1 cells}

Changes in protein expression during differentiation and starvation of 3T3-L1 cells were monitored by 2D electrophoresis. With the image analysis procedure, 93 spots were found matching the criteria for differentially expressed proteins. Maldi-TOF analysis of silver-stained protein spots revealed the identity of 33 proteins $(35 \%)$. Spots that could not be identified by the Maldi-TOF procedure were further analyzed by LC-MS/MS. In total, our mass spectrometry analysis resulted in the identity of 50 spots $(54 \%)$ representing 32 different genes. The location of these spots in a 2D pattern is depicted in figure 2 . Numbers of the protein spots on the gel images correspond with the proteins listed in table 1. The enlarged gel sections in figure 2 are from 2D gels derived from protein samples of our four experimental conditions and show the expression patterns of particular protein spots during the experiment. Boxed areas in the large gel image indicate the location of these sections in the respec-
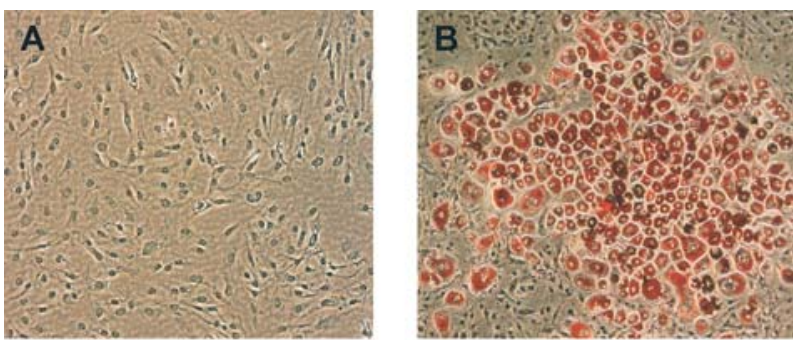

(A)
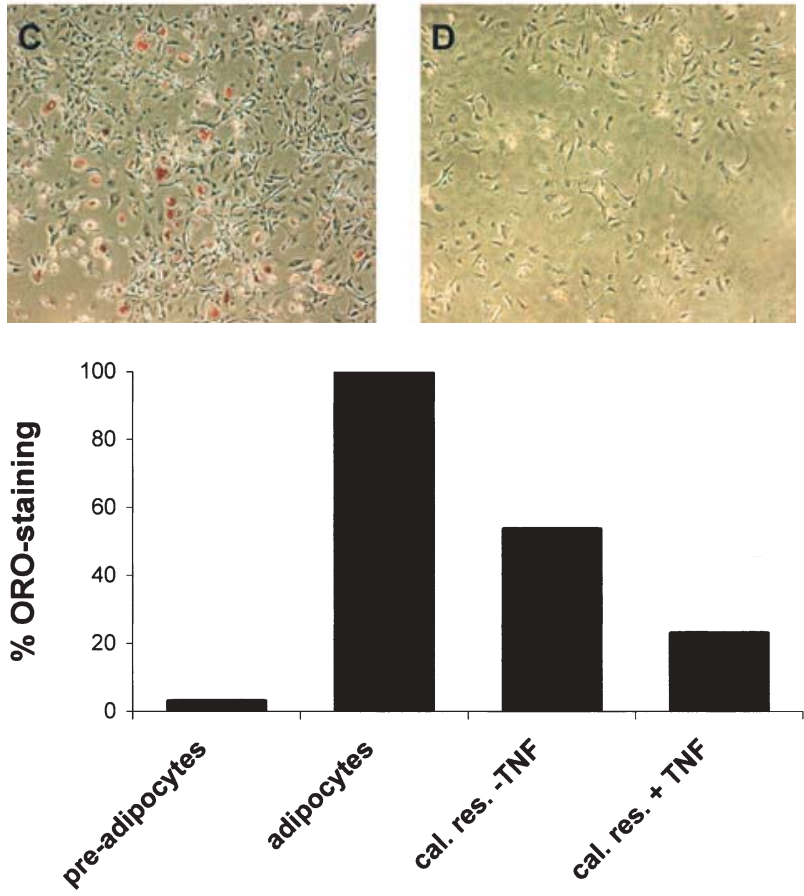

(B)

Figure 1. (A) Fat accumulation in 3T3-L1 cells during differentiation and starvation. Detection of triglycerides occurred with ORO in 3T3-L1 pre-adipocytes $(A), 3 \mathrm{~T} 3-\mathrm{L} 1$ adipocytes $(B)$, 3T3-L1 adipocytes subjected to caloric restriction without TNF- $\alpha(C)$ and 3T3-L1 adipocytes subjected to caloric restriction in the presence of TNF- $\alpha(D)$. $(B)$ Fat accumulation in 3T3-L1 cells during differentiation and starvation corrected for the number of living cells. The amount of fat storage in 3T3-L1 adipocytes was set to $100 \%$.

tive 2D gels. The gel sections are chosen so that examples of proteins from every cluster in table 1 are displayed. To our best knowledge, 16 proteins listed in table 1 have not been reported before as being expressed in 3T3-L1 cells.

The identified proteins were clustered into seven groups according to their expression patterns during 3T3-L1 differentiation and starvation (table 1). Similar identified spots in one cluster such as $\alpha$-enolase (table 1, cluster 3 , spot no. 7 and 8), nucleotide diphosphate kinase (NPDK) B (cluster 3, spot no. 13 and 14) and annexin II (cluster 6, spot no. 33, 34 and 35) are possibly isoforms or posttranslationaly modified forms of the same protein. Unfortunately, with the method we used, we were not able to distinguish between these possibilities and the functional significance with respect to 3T3-L1 cells remains elu- 


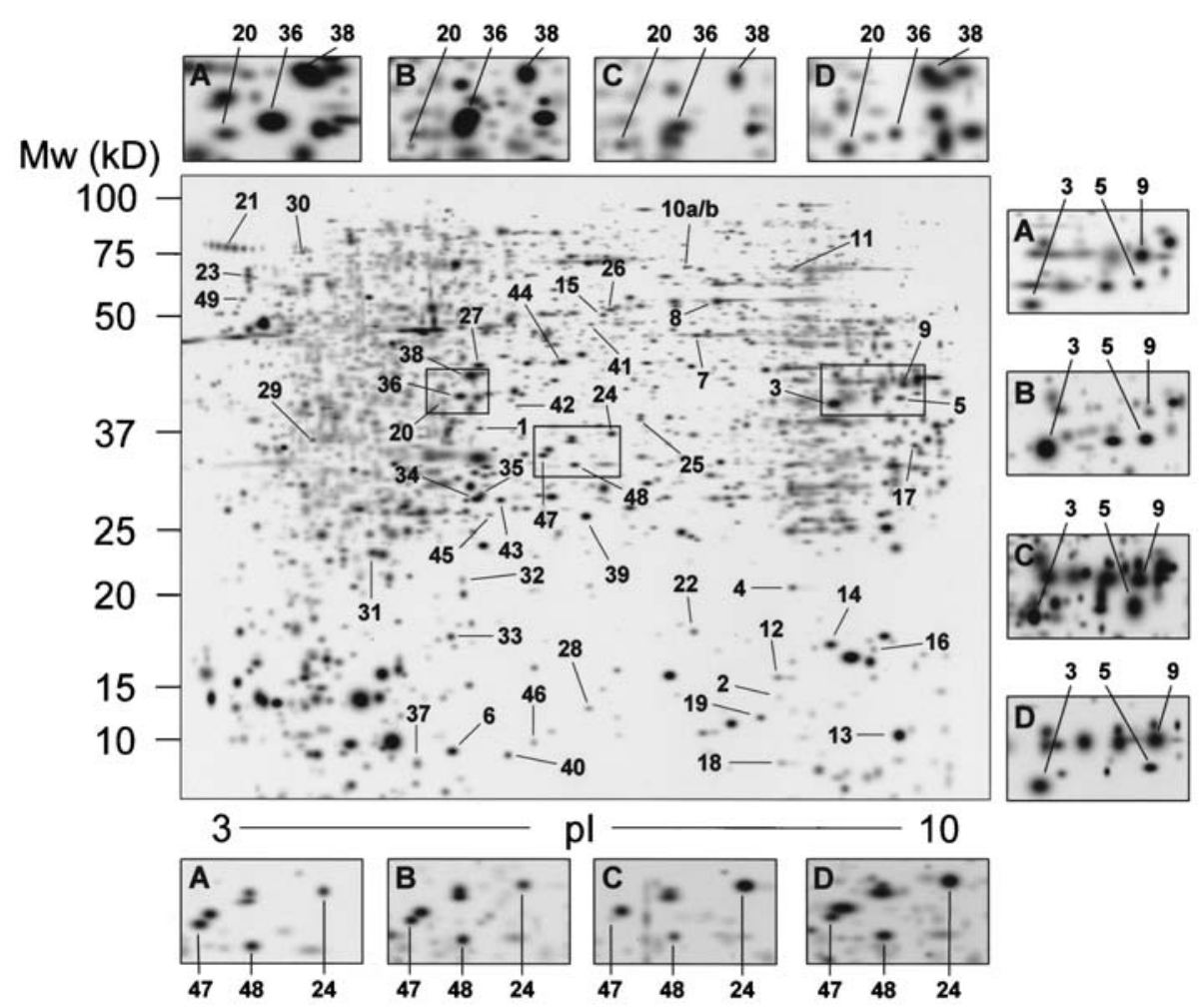

Figure 2. Identified proteins marked on a representative 2D gel image from pre-adipocytes. Enlarged gel sections are from 2D gels derived from protein samples of 3T3-L1 pre-adipocytes $(A)$, 3T3-L1 adipocytes $(B), 3 \mathrm{~T} 3$-L1 adipocytes subjected to caloric restriction without TNF- $\alpha(C)$ and 3T3-L1 adipocytes subjected to caloric restriction in the presence of TNF- $\alpha(D)$. The location of these sections in the respective 2D gels is indicated by boxed areas in the large gel image. The gel sections show expression patterns of proteins which are examples of all clusters in table 1 . Numbers on the gel images correspond to the protein numbers in table 1.

sive. Alternatively, due to technical conditions, some proteins may also be truncated during $2 \mathrm{D}$ electrophoresis which results in different spots derived from the same protein, e.g. glyceraldehyde 3-phosphate dehydrogenase (GAPDH) in cluster 1 and protein disulfide isomerase A3 in cluster 5 and 6 .

Expression patterns of identified proteins were analyzed using GenMAPP/Mappfinder in order to find relevant biological pathways involved in differentiation and starvation of 3T3-L1 (pre)-adipocytes. We found the glycolytic/gluconeogenesis pathway that met our criteria of at least three changed proteins (fig. 3).

\section{Proteins involved in 3T3-L1 differentiation}

Clearly, several proteins from the glycolysis/gluconeogenic pathway and associated reactions show a differential expression pattern during 3T3-L1 differentiation (fig. 3A, table 1, clusters 1 and 3). Spots identified as the glycolytic enzymes GAPDH and $\alpha$-enolase showed an increased expression during differentiation. Surprisingly, these enzymes were also found to be down-regulated during 3T3-L1 differentiation (fig 3A). Figure 4 shows the expression patterns of identified protein spots representing these two proteins during 3T3-L1 differentiation and starvation. Obviously, the appearance of $\alpha$-enolase (spot no. 1) and GAPDH (spot no. 3) paralleled the disappearance of $\alpha$-enolase (spot no. 7 and 8) and GAPDH (spot no. 9) during differentiation. In addition, during starvation, the expression pattern returned to the pre-adipocyte status. This suggests that one form of these proteins is converted into another form during 3T3-L1 differentiation and vice versa during starvation.

Expression of the final enzyme of the glycolysis pathway, pyruvate kinase was found to be down-regulated during 3T3-L1 differentiation, while expression of the mitochondrial malate dehydrogenase (MDH) was induced (fig. 3A). MDH converts malate into oxaloacetate which is used as a carrier for acetyl-CoA across the mitochondrial membrane. Acetyl CoA, once released in the cytosol, is the first substrate in fatty acid synthesis [24]. Another glycolysis-associated protein, phosphoglycerate dehydrogenase (spot 10a) was down-regulated during 3T3-L1 differentiation (fig. 3A).

Other metabolic enzymes that were down-regulated during 3T3-L1 differentiation were ornitine aminotransferase (OAT), NDPK A/B (table 1, cluster 3) and pyrophosphatase (cluster 4). OAT is involved in amino acid metabolism, while NDPK A and B play important roles in synthesis of non-adenylic nucleotides. The function of pyrophosphatase in 3T3-L1 cells remains elusive. 
Table 1. Proteins identified during 3T3-L1 differentiation and starvation.

\begin{tabular}{|c|c|c|c|c|c|c|}
\hline Cluster & Expression pattern & $\begin{array}{c}\text { Spot } \\
\text { on gel }\end{array}$ & $\begin{array}{c}\text { Accession } \\
\text { number }\end{array}$ & Protein ID. & Function & $\begin{array}{l}\text { Protein fo } \\
\text { in } 3 \mathrm{~T}_{3}-\mathrm{L} 1\end{array}$ \\
\hline 1 & & $\begin{array}{l}1 \\
2 \\
3 \\
4\end{array}$ & $\begin{array}{l}\text { p17182 } \\
\text { p16858 } \\
\text { p16858 } \\
\text { p30412 }\end{array}$ & $\begin{array}{l}\text { Enolase Alpha } \\
\text { Glyceraidehyde } 3 \text { phosphate dehydrogenase } \\
\text { Glyceraidehyde } 3 \text { phosphate dehydrogenase } \\
\text { Peptidy-prolyl cis-trans isomerase C }\end{array}$ & $\begin{array}{l}\text { Metabolism } \\
\text { Metabolsm } \\
\text { Metabolsm } \\
\text { Protein folding }\end{array}$ & $\begin{array}{l}{[23]} \\
{[60]} \\
{[60]} \\
{[23]}\end{array}$ \\
\hline & & $\begin{array}{l}5 \\
6\end{array}$ & $\begin{array}{l}\text { p08249 } \\
\text { p16045 }\end{array}$ & $\begin{array}{l}\text { Malate dehydrogenase, mirochondrial } \\
\text { Galectin-1 }\end{array}$ & $\begin{array}{l}\text { Metabolism } \\
\text { Cell growth }\end{array}$ & \\
\hline 2 & A & & & & & \\
\hline
\end{tabular}

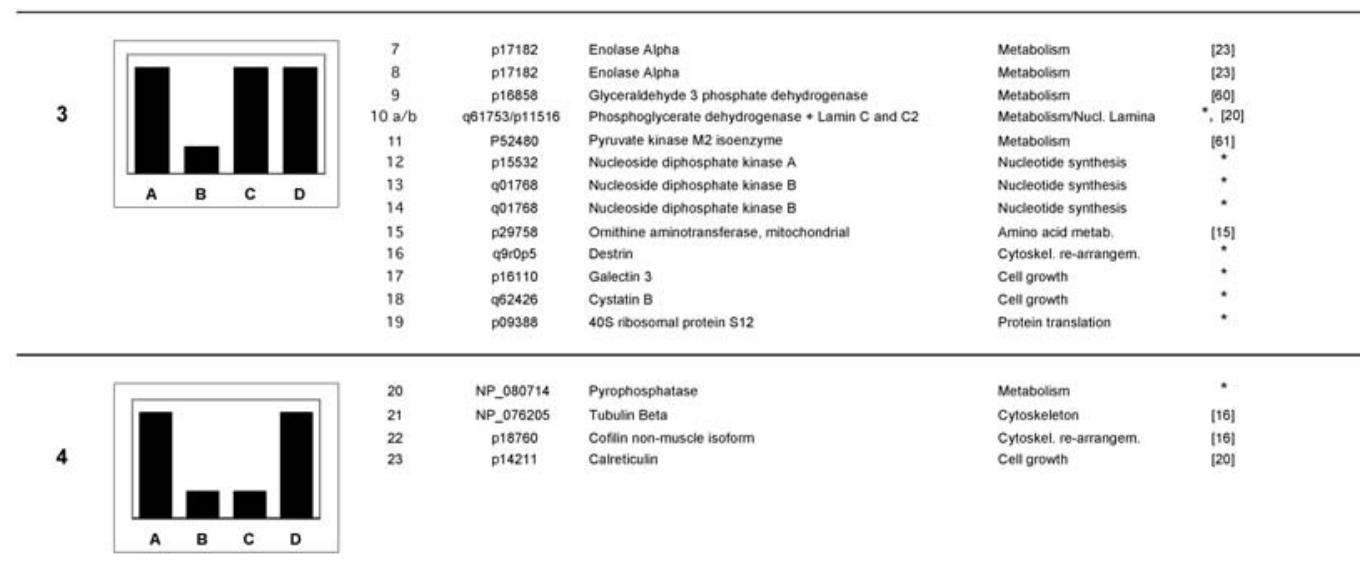

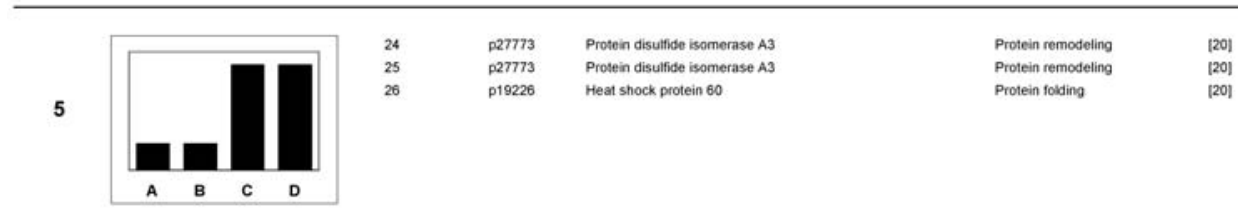

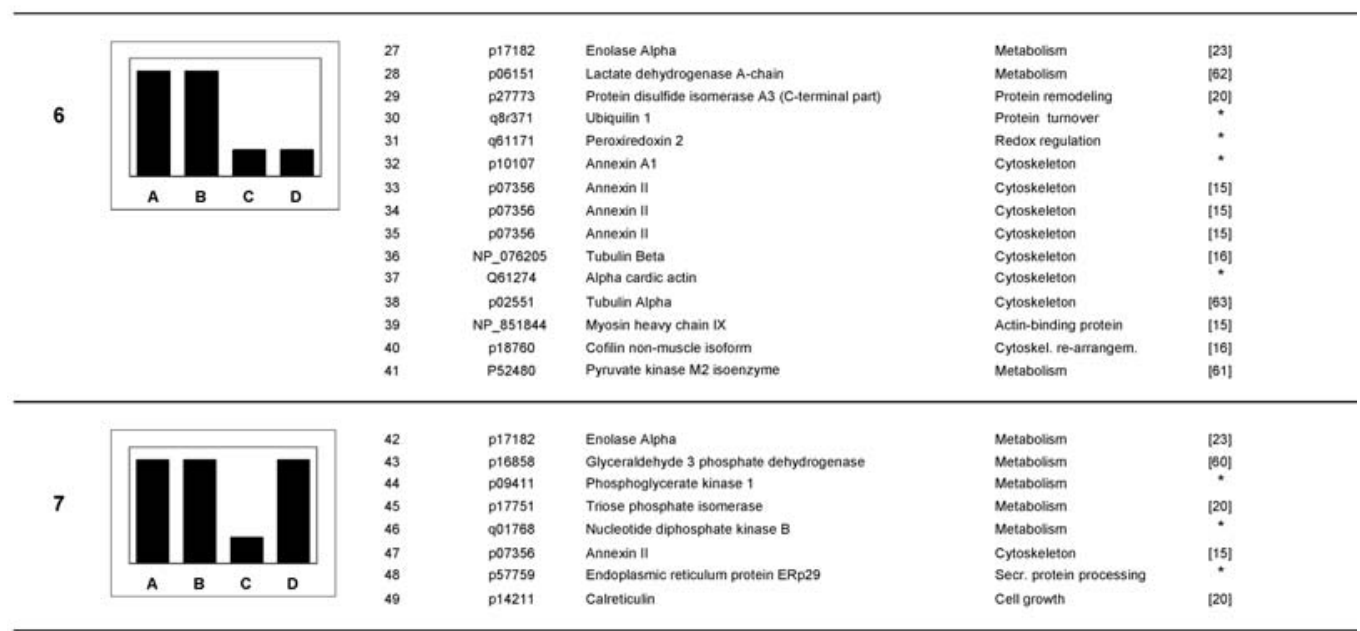

Proteins are grouped into seven clusters according to their expression profiles during the experiment. Bars represent relative expression ratios of the proteins under the following conditions: 3T3-L1 pre-adipocytes $(A), 3 \mathrm{~T} 3$-L1 adipocytes $(B), 3 \mathrm{~T} 3$-L1 adipocytes subjected to caloric restriction without TNF- $\alpha(C)$ and 3T3-L1 adipocytes subjected to caloric restriction in the presence of TNF- $\alpha(D)$. Accession numbers refer either to the Swiss-Prot database (p and q numbers) or to the NCBI protein database (NP numbers). Proteins indicated by asterisks have not been described before in 3T3-L1 cells. 


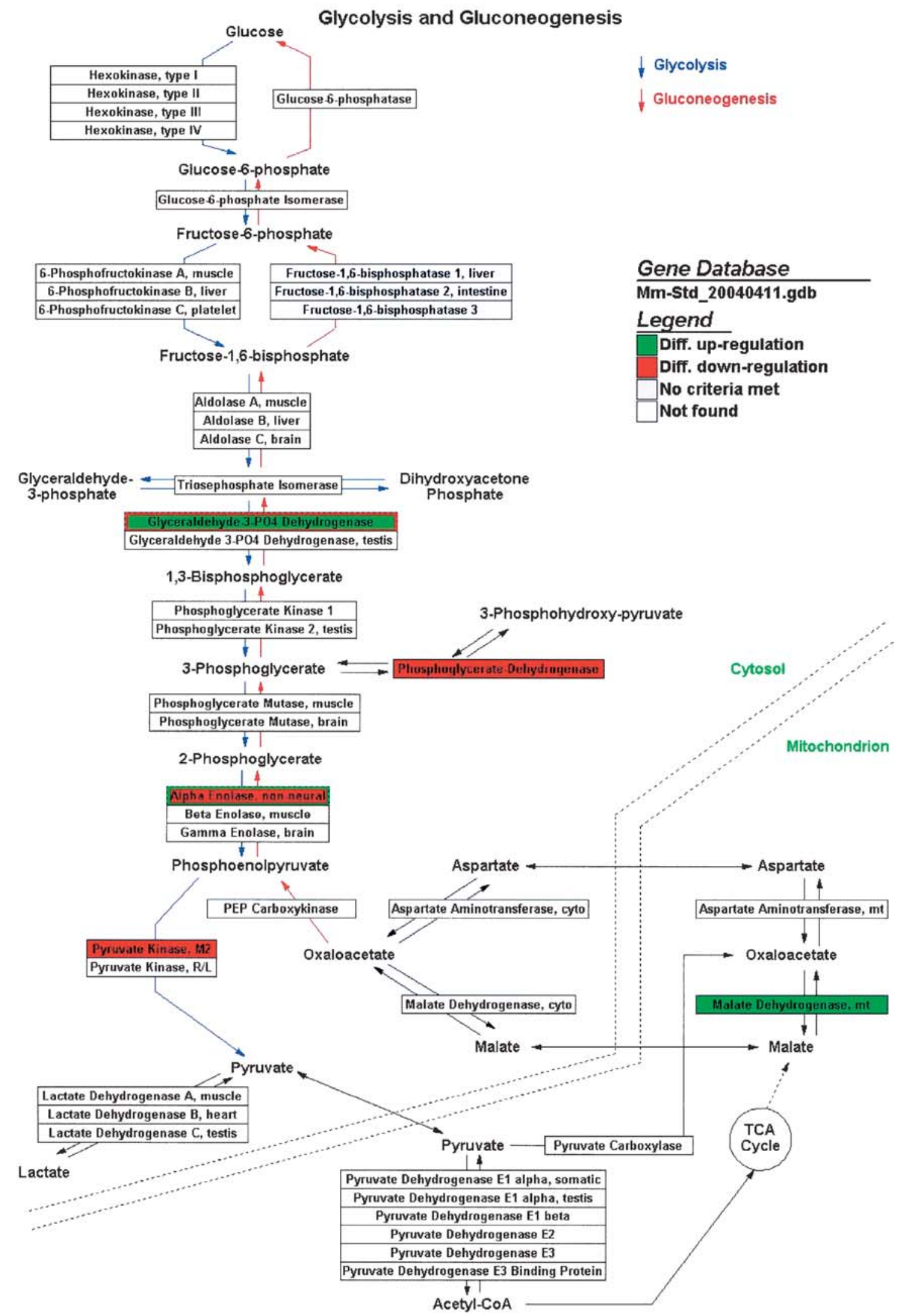

Figure 3. Regulated proteins in the glycolysis/gluconeogenesis pathway during 3T3-L1 differentiation $(A)$ and during 3T3-L1 starvation $(B)$. Proteins found to be up- as well as down-regulated during 3T3-L1 differentiation or starvation (GAPDH, $\alpha$-enolase and pyruvate kinase M2) are double colored. 


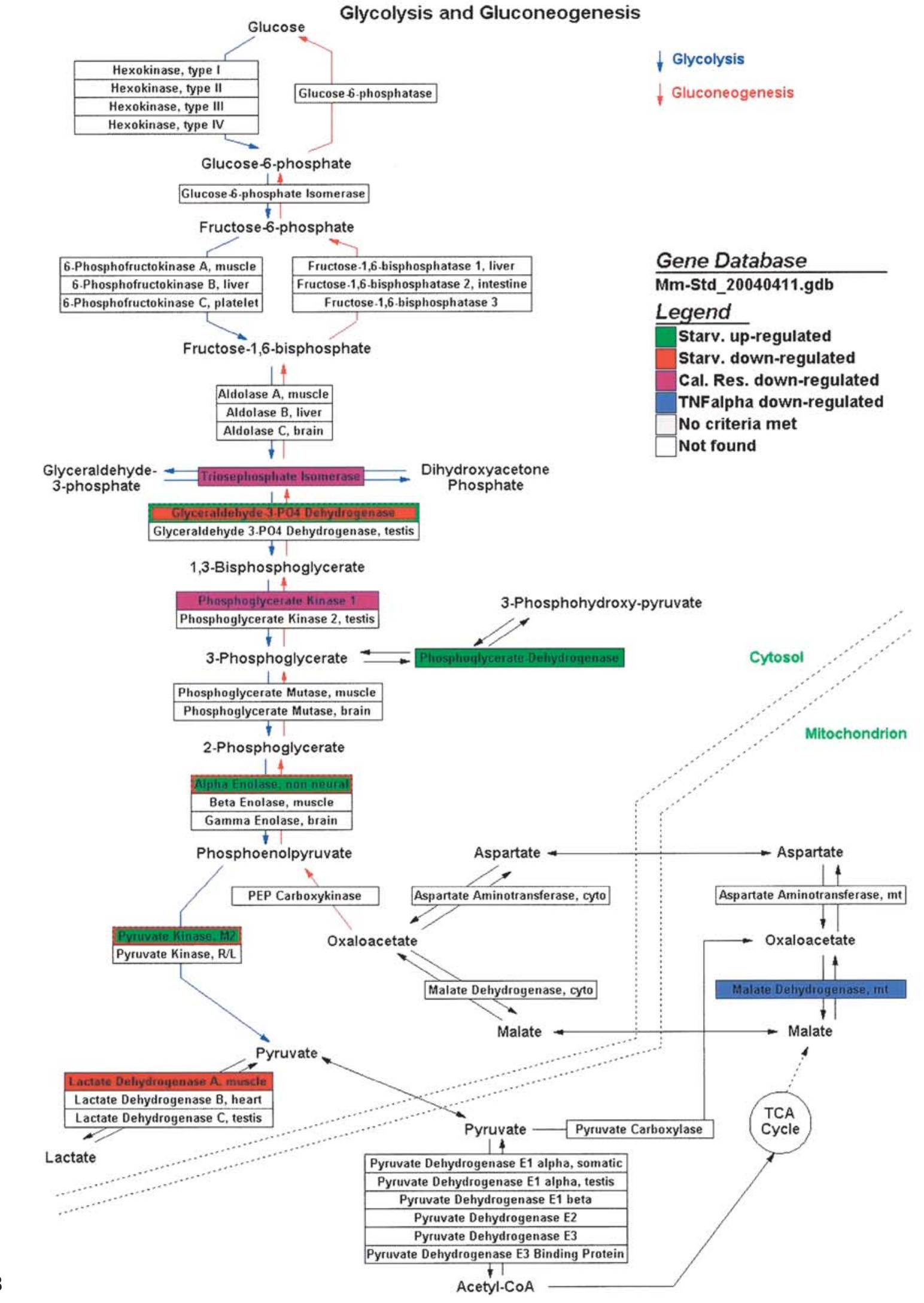

Figure 3 (continued) 


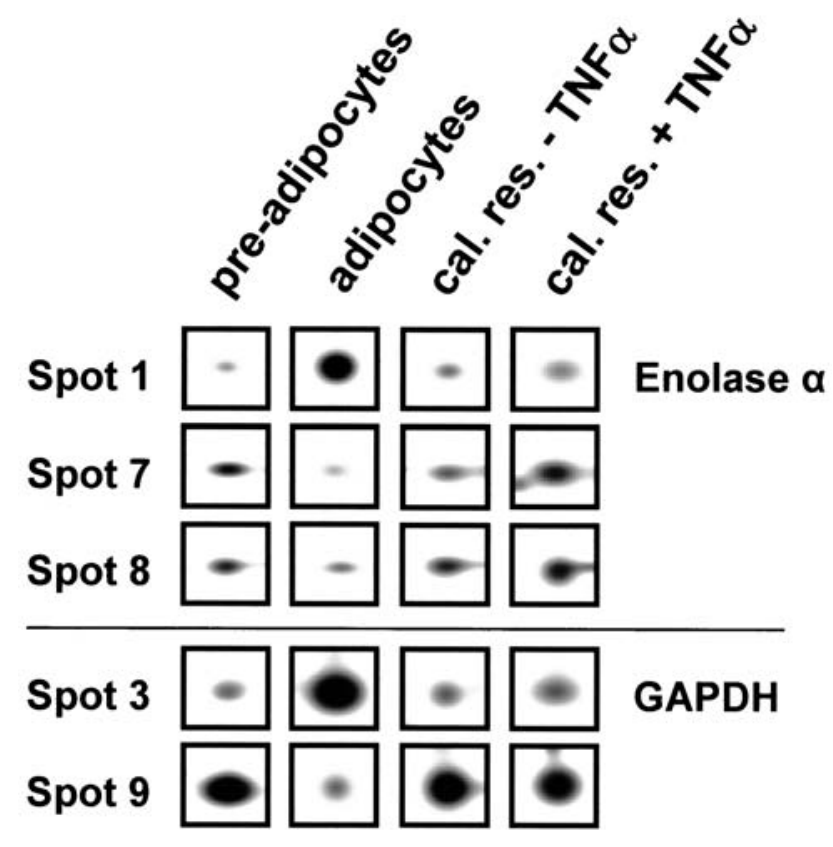

Figure 4. Reciprocal regulation of $\alpha$-enolase and GAPDH during 3T3-L1 differentiation and starvation.

In addition to metabolic enzymes, we observed a differential expression of proteins with growth-regulatory properties. These were peptidyl-prolyl cis-trans isomerase $\mathrm{C}$ and galectin-1 (clusters 1 and 2) which were induced during differentiation, and galectin-3, cystatin B (cluster 3) and calreticulin (cluster 4) which were downregulated. We also observed regulation of proteins with functions in cytoskeletal rearrangements. These were destrin/actin-depolymerizing factor (ADF) (cluster 3), $\beta$ tubulin and cofilin (cluster 4) which showed down-regulation during 3T3-L1 differentiation. Another protein down-regulated during differentiation was lamin $\mathrm{C}$ and C2 (spot 10b). This protein is present in a mixed spot with phosphoglycerate dehydrogenase (spot 10a). Lamin C, a component of the nuclear lamina, has been detected before by us in 3T3-L1 cells [17] and is also found in human adipose tissue [25]. Mutations in the gene encoding this protein cause familiar lipodystrophy [26].

\section{Proteins involved in 3T3-L1 starvation}

Proteins in cluster 1 and 3 (table 1) with altered expression during differentiation (compare bars $\mathrm{A}$ and $\mathrm{B}$ ) showed a reciprocal regulation when differentiated 3T3L1 cells were subjected to starvation (compare bars B vs bars $\mathrm{C}$ and $\mathrm{D}$ ). This suggests a specific functional association of these proteins with the transition of 3T3-L1 preadipocytes to adipocytes. In addition, both starvation protocols resulted in a return of these proteins to their preadipocyte status.

Figure 3B shows proteins with different expression patterns in the glycolytic/gluconeogenic pathway during starvation. Compared to 3T3-L1 differentiation (fig. 3A), beside common regulated proteins, some proteins are specifically influenced by starvation. These are triosephosphate isomerase, phosphoglycerate kinase and lactate dehydrogenase.

Next to metabolic enzymes, other proteins were specifically regulated by starvation. Cluster 5 shows up-regulation of the chaperone protein disulfide isomerase $\mathrm{A} 3$ and heat shock protein 60 . These proteins are linked to cellular stress, a condition that may be induced by caloric restriction of 3T3-L1 cells. Cluster 6 shows proteins that are related to the cytoskeletal network such as annexins, tubulins, actin, myosin and cofilin. In addition, we found the redox regulator peroxiredoxin 2 and ubiquilin, a protein involved in protein degradation. These proteins were all down-regulated during starvation.

\section{TNF- $\alpha$ regulates a different set of proteins during caloric restriction}

We investigated the effect of a known lipolysis inducer (TNF- $\alpha$ ) on the proteome of differentiated 3T3-L1 cells on a background of caloric restriction (table 1, bars B vs bars D). We also compared the effect of both starvation protocols (caloric restriction in the absence or in the presence of TNF- $\alpha$ ) on 3T3-L1 cells (table 1, bars C vs bars D). Beside common regulated proteins during both starvation protocols (table 1, clusters 1, 3, 5 and 6), a set of differentially expressed proteins was observed between caloric restriction and caloric restriction combined with TNF- $\alpha$ (see table 1, clusters 2, 4 and 7).

One protein where expression was specifically down-regulated by TNF- $\alpha$ was galectin-1. During starvation, expression of galectin-1 was not influenced by caloric restriction while its expression was reduced by TNF- $\alpha$ (table 1 , cluster 2). On the other hand, pyrophosphatase, $\beta$-tubulin, calreticulin and cofilin were specifically up-regulated by TNF- $\alpha$ (table 1, cluster 4 ). A striking difference in protein expression was observed with respect to metabolic enzymes (see also fig. 3B). For example, expression of $\mathrm{MDH}$ (table 1, cluster 2) was not changed during caloric restriction but was down-regulated by TNF- $\alpha$.

Cluster 7 shows several metabolic proteins that were down-regulated when differentiated 3T3-L1 cells were subjected to caloric restriction but did not show a change in expression when these cells were treated with TNF- $\alpha$. These are the glycolytic enzymes $\alpha$-enolase (spot no. 42), GAPH (spot no. 43), phosphoglycerate kinase 1, triosephosphate isomerase and the nucleotide synthesizer NDPK B (spot no. 46). Other proteins specifically downregulated by caloric restriction without TNF- $\alpha$ are the endoplasmic reticulum proteins ERp29 and calreticulin and the cytoskeleton-related protein annexin II. TNF- $\alpha$ seems to prevent down-regulation of these proteins when differentiated 3T3-L1 cells are subjected to the combination of caloric restriction and TNF- $\alpha$. 


\section{Discussion}

The complex etiology of obesity requires a thorough understanding of the molecular mechanisms of the adipogenic process. To gain a broader understanding of the molecular events during adipogenesis and to overcome the limits of transcriptomics with respect to cellular behavior, we examined changes in the proteome of 3T3-L1 cells. Concerning differentiation of 3T3-L1 cells, our data show similar expression patterns for several proteins which confirm previous results [12-14]. However, we also identified proteins that are specifically involved in starvation of 3T3-L1 cells. Moreover, we found proteins whose expression has not been reported before in 3T3-L1 cells. Therefore, our data add valuable information for a better understanding of the molecular mechanism involved in fat storage and fat depletion in 3T3-L1 adipocytes.

Four categories of proteins were identified during 3T3L1 differentiation and starvation: metabolic enzymes, proteins with growth regulatory properties, proteins with a function in cytoskeletal rearrangements and protein modifiers. With respect to metabolic enzymes, the increased expression of GAPDH, $\alpha$-enolase and MDH during differentiation is in agreement with enhanced glycolytic activity and fatty acid synthesis [24]. The expression pattern of these proteins resembles the mRNA expression profiles from the same genes during adipogenesis in vitro and in vivo [6]. The down-regulation of phosphoglycerate dehydrogenase may reduce the exit of 3-phosphoglycerate from the glycolytic pathway and consequently stimulate the conversion of glucose into acetylCoA. The pyruvate dehydrogenase complex (PDC) is the link between glycolysis and fatty acid synthesis by conversion of pyruvate into acetyl-CoA. One of the control mechanisms for regulation of the PDC is the energy status in the cell. GTP, in particular, is able to inhibit PDC activity [24] and GTP-binding proteins are known to regulate PDC activity [27]. The main function of NDPK A and B is synthesis of non-adenylic nucleotides [28]. Therefore, down-regulation of NDPK A and B during differentiation of 3T3-L1 cells results in a decreased level of nucleotides that may counteract the inhibition of PDC and promote fatty acid synthesis. In addition, NDPK A and $\mathrm{B}$ are also able to regulate cell growth, which will be discussed below. The surprising disappearance of the spot representing the major glycolytic enzyme pyruvate kinase during differentiation might be due to dephosphorylation, in analogy with its isoform pyruvate kinase L. This enzyme is activated by insulin via a dephosphorylation event [29, and references therein].

(De-)phosphorylation may be one explanation for the observed shift in the position of certain spots in our 2D gels. However, the mass difference between the spots identified as GAPDH and $\alpha$-enolase showing a reciprocal ex- pression pattern during differentiation and subsequent caloric restriction (fig. 4) is too large to be explained by (de-)phosphorylation. For both enzymes, several isoforms have been identified with suggested different cellular locations and functions such as apoptosis, membrane dynamics, excretion, receptor function and growth regulation [reviewed in refs. 30,31]. Which isoforms are involved in each process and whether these isoforms are active in 3T3-L1 cells is currently not known. Alternatively, degradation of these proteins cannot be excluded but because of the reciprocal expression patterns, this is unlikely to be due to technical conditions. Instead, this may imply the activity of specific proteases during 3T3L1 differentiation and starvation.

Based on our protein expression data, we conclude that the glycolytic pathway is not completely reciprocally regulated when differentiated 3T3-L1 cells are subjected to caloric restriction. Beside common regulated proteins during both conditions, such as GAPDH and $\alpha$-enolase, we observed three glycolytic proteins, triosephosphate isomerase, phosphoglycerate kinase 1 and lactate dehydrogenase, whose expression was stable during 3T3-L1 differentiation but was altered during caloric restriction. In addition, the up-regulated expression of $\mathrm{MDH}$ during differentiation was not reversed during caloric restriction which indicates a residual activity in fatty acid synthesis. These results clearly demonstrate that the regulation of the glycolysis pathway during caloric restriction of 3T3L1 cells differs from the regulation during differentiation. For other identified proteins, a non-reciprocal regulation was also observed when differentiated 3T3-L1 cells were subjected to caloric restriction. This shows that although caloric restriction results in fat release, it induces only a limited pre-adipocyte-like protein expression pattern.

Previously, at the mRNA level, TNF- $\alpha$ was shown to induce a conversion to a pre-adipocyte genotype when added to differentiated 3T3-L1 cells [32]. We found a similar effect at the protein level. Compared to solely caloric restriction, a combination of caloric restriction and TNF- $\alpha$ showed that more proteins change to a preadipocyte-like expression pattern. Moreover, TNF- $\alpha$ counteracted effects of caloric restriction on differentiated 3T3-L1 (see table 1, clusters 2, 4 and 7).

We observed a specific TNF- $\alpha$-mediated up-regulation of calreticulin (table 1, clusters 4 and 7). This protein is able to repress translation of CCAAT/enhancer-binding protein $(\mathrm{C} / \mathrm{EBP}) \alpha$ and $\mathrm{C} / \mathrm{EBP} \beta$ [33]. Repression of $\mathrm{C} / \mathrm{EBP}$ has also been observed when 3T3-L1 adipocytes were subjected to TNF- $\alpha[15,34]$. We expect that calreticulin is involved in this process. Overexpression of either CEBP $\alpha$ or CEBP $\beta$ in 3T3-L1 cells is sufficient to induce their differentiation into mature fat cells. In conjunction with peroxisome proliferator-activated receptor $\gamma$ $(\operatorname{PPAR} \gamma)$, both proteins are involved in the transcriptional cascade that plays an important role in the differentiation 
of 3T3-L1 cells [reviewed in ref. 35]. In our experiments, TNF- $\alpha$ regulates a set of proteins that seem to induce a pre-adipocyte phenotype that results in a further decrease in intracellular fat content. This is in agreement with the observed inhibition of PPAR $\gamma$ by TNF- $\alpha$ in mature 3T3L1 adipocytes [36, 37]. Furthermore, stimulation of PPAR $\gamma$ inhibits the action of TNF- $\alpha$ on 3T3-L1 adipocytes [38]. Thus, in contrast to solely caloric restriction, we expect that a forced down-regulation of $\mathrm{C} / \mathrm{EBP}$ proteins and PPAR $\gamma$ by TNF- $\alpha$ might play a role in a stronger depletion of fat content in 3T3-L1 cells (see fig. 1).

During differentiation, 3T3-L1 cells loose proliferative potential and acquire resistance against apoptotic stimuli which is accompanied by induced expression of a neuronal apoptosis inhibitory protein [39]. We found seven differentially expressed proteins which possess growthregulatory properties: galectin 1 and 3 , NDPK A and B, calreticulin, peptidyl-prolyl cis-trans isomerase $\mathrm{C}$ and cystatin B. Dependent on the cell type, galectin 1 and 3 are anti-apoptotic [40]. Galectin 1 arrests T cells in the S and $\mathrm{G} 2 / \mathrm{M}$ phase of the cell cycle, while low expression of galectin 1 induces cell proliferation [41]. Transfection with antisense galectin 3 cDNA inhibited the proliferation of MDA-MB435 breast cancer cells [42]. NDPK gene expression is positively correlated with proliferating tumor cells, while down-regulation of NDPK proteins by RNA antisense techniques suppresses tumor cell growth as reviewed by Kimura et al. [43]. Mouse embryonic fibroblasts deficient in calreticulin are resistant to apoptosis, probably via $\mathrm{Ca}^{2+}$-mediated signaling [44], and overexpression of calreticulin is associated with increased malignancy of breast cancer cells $[45,46]$. Peptidyl-prolyl cis-trans isomerase $\mathrm{C}$ is a member of a large conserved family of peptidyl-prolyl cis-trans isomerases which includes FK506-binding proteins (FKBP), cyclophilins and parvulins [47]. Recently, cyclophilin D and FKBP38 were shown to be anti-apoptotic $[48,49]$. Finally, cystatin $\mathrm{B}$ is suggested to be involved in progression of tumor cell growth $[50,51]$. When differentiated 3T3-L1 cells are subsequently treated with our starvation protocols, the expression of these proteins returns to their pre-adipocyte status. Based on their expression profiles during our experiments, the seven proteins indicated here are likely actively involved in cell growth arrest during 3T3-L1 differentiation and in an anti-apoptotic phenotype of differentiated 3T3-L1 cells. Upon starvation, the expression patterns of these proteins are switched to a profile that is associated with induced cell proliferation and increased sensitivity to apoptosis, particularly when TNF- $\alpha$ is used. Indeed, TNF- $\alpha$ is known to activate pre-adipocyte genes in 3T3-L1 adipocytes [32] and to induce apoptosis in 3T3-L1 pre-adipocytes [52].

During 3T3-L1 differentiation, a dramatic remodeling of the cytoskeleton occurs. While the tubulin network is ex- panded by the action of insulin [53], the actin fiber network is depolymerized and transformed into a cortical network lining the inner face of the plasma membrane $[54,55]$. We found three proteins, annexin II, cofilin and destrin/ADF, which are actively involved in actin dynamics $[56,57]$. Recently, increased expression of coactosin was found during 3T3-L1 differentiation. Overexpression of this protein induced a depolymerization of actin [13]. This indicates that several different proteins are involved in remodeling of the cytoskeleton during 3T3-L1 differentiation. Little is known, however, about the behavior of the cytoskeleton during fat depletion in 3T3-L1 cells. Brasaemle et al. [58] showed that cytoskeleton-disrupting agents did not inhibit isoproterenol-induced lipolysis in 3T3-L1 cells. Thus a remodeling of the cytoskeleton does not hinder lipolysis. The decreased expression of annexin II, actin, tubulin and myosin IX, an actin-binding protein [59], that we observed during starvation of differentiated 3T3-L1 cells is in agreement with this.

Our data show that the glycolysis/gluconeogenic pathways are differentially regulated during 3T3-L1 differentiation and subsequent starvation. Differentiated 3T3-L1 cells express a protein profile that is associated with cell growth arrest, resistance to apoptosis and a remodeling of the cytoskeleton. Most of the proteins involved in these processes show a reversed expression pattern upon 3T3L1 starvation, especially with TNF- $\alpha$. In conclusion, our results demonstrate that an independent survey of protein expression provides valuable information for the broader understanding of adipogenesis. New proteins were discovered with expected important roles in 3T3-L1 differentiation and starvation. These provide potential new targets for future intervention studies with respect to obesity.

Acknowledgements. Dr. P. Verhaert (University of Leuven, Belgium) is acknowledged for assistance with protein identification by mass spectrometry and Dr. W. Voncken (Maastricht University) for assistance with microscopy. This study was supported by the Maastricht Proteomics Center, the Brede Onderzoek Strategie and the research institute NUTRIM of the Maastricht University.

1 Kopelman P. G. (2000) Obesity as a medical problem. Nature 404: 635-643

2 Spiegelman B. M. and Flier J. S. (2001) Obesity and the regulation of energy balance. Cell 104: 531-543

3 Prins J. B. and O'Rahilly S. (1997) Regulation of adipose cell number in man. Clin. Sci. 92: 3-11

4 Guo X. and Liao K. (2000) Analysis of gene expression profile during 3T3-L1 preadipocyte differentiation. Gene 251: 45-53

5 Burton G. R., Guan Y., Nagarajan R. and McGehee R. E. Jr (2002) Microarray analysis of gene expression during early adipocyte differentiation. Gene 293: 21-31

6 Soukas A., Socci N. D., Saatkamp B. D., Novelli S. and Friedman J. M. (2001) Distinct transcriptional profiles of adipogenesis in vivo and in vitro. J. Biol. Chem. 276: $34167-34174$

7 Nadler S. T., Stoehr J. P., Schueler K. L., Tanimoto G., Yandell B. S. and Attie A. D. (2000) The expression of adipogenic genes 
is decreased in obesity and diabetes mellitus. Proc. Natl. Acad. Sci. USA 97: 11371-11376

8 Gygi S. P., Rochon Y., Franza B. R. and Aebersold R. (1999) Correlation between protein and mRNA abundance in yeast. Mol. Cell. Biol. 19: 1720-1730

9 Futcher B., Latter G. I., Monardo P., McLaughlin C. S. and Garrels J. I. (1999) A sampling of the yeast proteome. Mol. Cell. Biol. 19: 7357-7368

10 Richards J., Le Naour F., Hanash S. and Beretta L. (2002) Integrated genomic and proteomic analysis of signaling pathways in dendritic cell differentiation and maturation. Ann. N. Y. Acad. Sci. 975: 91-100

11 Sidhu R. S. (1979) Two-dimensional electrophoretic analyses of proteins synthesized during differentiation of 3T3-L1 preadipocytes. J. Biol. Chem. 254: 11111-11118

12 Wilson-Fritch L., Burkart A., Bell G., Mendelson K., Leszyk J., Nicoloro S. et al. (2003) Mitochondrial biogenesis and remodeling during adipogenesis and in response to the insulin sensitizer rosiglitazone. Mol. Cell. Biol. 23: 1085-1094

13 Welsh G. I., Griffiths M. R., Webster K. J., Page M. J. and Tavare J. M. (2004) Proteome analysis of adipogenesis. Proteomics 4: 1042-1051

14 Choi K. L., Wang Y., Tse C. A., Lam K. S., Cooper G. J. and Xu A. (2004) Proteomic analysis of adipocyte differentiation: evidence that alpha 2 macroglobulin is involved in the adipose conversion of 3T3 L1 preadipocytes. Proteomics 4: 1840-1848

15 Ron D., Brasier A. R., McGehee R. E. Jr and Habener J. F. (1992) Tumor necrosis factor-induced reversal of adipocytic phenotype of 3T3-L1 cells is preceded by a loss of nuclear CCAAT/enhancer binding protein (C/EBP). J. Clin. Invest. 89: 223-233

16 Petruschke T. and Hauner H. (1993) Tumor necrosis factor-alpha prevents the differentiation of human adipocyte precursor cells and causes delipidation of newly developed fat cells. J. Clin. Endocrinol. Metab. 76: 742-747

17 Bouwman F., Renes J. and Mariman E. (2004) A combination of protein profiling and isotopomer analysis using matrix-assisted laser desorption/ionization-time of flight mass spectrometry reveals an active metabolism of the extracellular matrix of 3T3-L1 adipocytes. Proteomics 4: 3855-3863

18 Zorenc A., Bouwman F. and Bakker A. (2002) Induction of lipodystrophy in 3T3-L1 cells. Int. J. Obes. Rel. Metab. Dis. 26: 654

19 Shevchenko A., Wilm M., Vorm O. and Mann M. (1996) Mass spectrometric sequencing of proteins silver-stained polyacrylamide gels. Anal. Chem. 68: $850-858$

20 Wang P., Mariman E., Keijer J., Bouwman F., Noben J. P., Robben J. et al. (2004) Profiling of the secreted proteins during 3T3-L1 adipocyte differentiation leads to the identification of novel adipokines. Cell. Mol. Life Sci. 61: 2405-2417

21 Dumont D., Noben J. P., Raus J., Stinissen P. and Robben J. (2004) Proteomic analysis of cerebrospinal fluid from multiple sclerosis patients. Proteomics 4: 2117-2124

22 Dahlquist K. D., Salomonis N., Vranizan K., Lawlor S. C. and Conklin B. R. (2002) GenMAPP, a new tool for viewing and analyzing microarray data on biological pathways. Nat. Genet. 31: $19-20$

23 Doniger S. W., Salomonis N., Dahlquist K. D., Vranizan K., Lawlor S. C. and Conklin B. R. (2003) MAPPFinder: using Gene Ontology and GenMAPP to create a global gene-expression profile from microarray data. Genome Biol 4: R7

24 Stryer L. (1988) Biochemistry, Freeman, New York

25 Lelliott C. J., Logie L., Sewter C. P., Berger D., Jani P., Blows F. et al. (2002) Lamin expression in human adipose cells in relation to anatomical site and differentiation state. J. Clin. Endocrinol. Metab. 87: 728-734

26 Speckman R. A., Garg A., Du F., Bennett L., Veile R., Arioglu E. et al. (2000) Mutational and haplotype analyses of families with familial partial lipodystrophy (Dunnigan variety) reveal recurrent missense mutations in the globular C-terminal domain of lamin A/C. Am. J. Hum. Genet. 66: 1192-1198

27 Curto M., Piccinini M., Rabbone I., Mioletti S., Mostert M., Bruno R. et al. (1997) G proteins and regulation of pyruvate dehydrogenase activity by insulin in human circulating lymphocytes. Int. J. Biochem. Cell Biol. 29: 1207-1217

28 Lacombe M. L., Milon L., Munier A., Mehus J. G. and Lambeth D. O. (2000) The human Nm23/nucleoside diphosphate kinases. J. Bioenerg. Biomembr. 32: 247-258

29 Carrillo J. J., Ibares B., Esteban-Gamboa A. and Feliu J. E. (2001) Involvement of both phosphatidylinositol 3-kinase and p44/p42 mitogen-activated protein kinase pathways in the short-term regulation of pyruvate kinase L by insulin. Endocrinology 142: 1057-1064

30 Sirover M. A. (1999) New insights into an old protein: the functional diversity of mammalian glyceraldehyde-3-phosphate dehydrogenase. Biochim. Biophys. Acta 1432: 159-184

31 Pancholi V. (2001) Multifunctional alpha-enolase: its role in diseases. Cell. Mol. Life Sci. 58: 902-920

32 Ruan H., Hacohen N., Golub T. R., Van Parijs L. and Lodish H. F. (2002) Tumor necrosis factor-alpha suppresses adipocytespecific genes and activates expression of preadipocyte genes in 3T3-L1 adipocytes: nuclear factor-kappaB activation by TNF-alpha is obligatory. Diabetes 51: 1319-1336

33 Timchenko L. T., Iakova P., Welm A. L., Cai Z. J. and Timchenko N. A. (2002) Calreticulin interacts with C/EBPalpha and $\mathrm{C} / \mathrm{EBPbeta} \mathrm{mRNAs}$ and represses translation of $\mathrm{C} / \mathrm{EBP}$ proteins. Mol. Cell. Biol. 22: 7242-7257

34 Stephens J. M. and Pekala P. H. (1991) Transcriptional repression of the GLUT4 and C/EBP genes in 3T3-L1 adipocytes by tumor necrosis factor-alpha. J. Biol. Chem. 266: 21839-21845

35 Rosen E. D. and Spiegelman B. M. (2000) Molecular regulation of adipogenesis. Annu. Rev. Cell Dev. Biol. 16: 145-171

36 Zhang B., Berger J., Hu E., Szalkowski D., White-Carrington S., Spiegelman B. M. et al. (1996) Negative regulation of peroxisome proliferator-activated receptor-gamma gene expression contributes to the antiadipogenic effects of tumor necrosis factor-alpha. Mol. Endocrinol. 10: 1457-1466

37 Xing H., Northrop J. P., Grove J. R., Kilpatrick K. E., Su J. L. and Ringold G. M. (1997) TNF alpha-mediated inhibition and reversal of adipocyte differentiation is accompanied by suppressed expression of PPARgamma without effects on Pref-1 expression. Endocrinology 138: 2776-2783

38 Souza S. C., Yamamoto M. T., Franciosa M. D., Lien P. and Greenberg A. S. (1998) BRL 49653 blocks the lipolytic actions of tumor necrosis factor-alpha: a potential new insulin-sensitizing mechanism for thiazolidinediones. Diabetes 47: 691-695

39 Magun R., Gagnon A., Yaraghi Z. and Sorisky A. (1998) Expression and regulation of neuronal apoptosis inhibitory protein during adipocyte differentiation. Diabetes 47: 1948-1952

40 Hsu D. K. and Liu F. T. (2004) Regulation of cellular homeostasis by galectins. Glycoconj. J. 19: 507-515

41 Yang R. Y. and Liu F. T. (2003) Galectins in cell growth and apoptosis. Cell. Mol. Life Sci. 60: 267-276

42 Honjo Y., Nangia-Makker P., Inohara H. and Raz A. (2001) Down-regulation of galectin-3 suppresses tumorigenicity of human breast carcinoma cells. Clin. Cancer Res. 7: 661-668

43 Kimura N., Shimada N., Fukuda M., Ishijima Y., Miyazaki H., Ishii A. et al. (2000) Regulation of cellular functions by nucleoside diphosphate kinases in mammals. J. Bioenerg. Biomembr. 32: 309-315

44 Nakamura K., Bossy-Wetzel E., Burns K., Fadel M. P., Lozyk M., Goping I. S. et al. (2000) Changes in endoplasmic reticulum luminal environment affect cell sensitivity to apoptosis. J. Cell Biol. 150: 731-740

45 Franzen B., Linder S., Alaiya A. A., Eriksson E., Uruy K., Hirano T. et al. (1996) Analysis of polypeptide expression in benign and malignant human breast lesions: down-regulation of cytokeratins. Br. J. Cancer 74: 1632-1638 
46 Franzen B., Linder S., Alaiya A. A., Eriksson E., Fujioka K. Bergman A. C. et al. (1997) Analysis of polypeptide expression in benign and malignant human breast lesions. Electrophoresis 18: $582-587$

47 Galat A. (2003) Peptidylprolyl cis/trans isomerases (immunophilins): biological diversity-targets-functions. Curr. Top. Med. Chem. 3: 1315-1347

48 Schubert A. and Grimm S. (2004) Cyclophilin D, a component of the permeability transition-pore, is an apoptosis repressor. Cancer Res. 64: 85-93

49 Shirane M. and Nakayama K. I. (2003) Inherent calcineurin inhibitor FKBP38 targets $\mathrm{Bcl}-2$ to mitochondria and inhibits apoptosis. Nat. Cell Biol. 5: 28-37

50 Kos J. and Lah T. T. (1998) Cysteine proteinases and their endogenous inhibitors: target proteins for prognosis, diagnosis and therapy in cancer. Oncol. Rep. 5: 1349-1361

51 Calkins C. C., Sameni M., Koblinski J., Sloane B. F. and Moin K. (1998) Differential localization of cysteine protease inhibitors and a target cysteine protease, cathepsin B, by immuno-confocal microscopy. J. Histochem. Cytochem. 46: $745-751$

52 Niesler C. U., Urso B., Prins J. B. and Siddle K. (2000) IGF-I inhibits apoptosis induced by serum withdrawal, but potentiates TNF-alpha-induced apoptosis, in 3T3-L1 preadipocytes. J. Endocrinol. 167: 165-174

53 Olson A. L., Eyster C. A., Duggins Q. S. and Knight J. B. (2003) Insulin promotes formation of polymerized microtubules by a phosphatidylinositol 3-kinase-independent, actin-dependent pathway in 3T3-L1 adipocytes. Endocrinology 144: 50305039

54 Kawaguchi N., Sundberg C., Kveiborg M., Moghadaszadeh B., Asmar M., Dietrich N. et al. (2003) ADAM12 induces actin cytoskeleton and extracellular matrix reorganization during early adipocyte differentiation by regulating beta1 integrin function. J. Cell Sci. 116: 3893-3904
55 Kanzaki M. and Pessin J. E. (2001) Insulin-stimulated GLUT4 translocation in adipocytes is dependent upon cortical actin remodeling. J. Biol. Chem. 276: 42436-42444

56 Gerke V. and Moss S. E. (2002) Annexins: from structure to function. Physiol. Rev. 82: 331-371

57 Remedios C. G. dos, Chhabra D., Kekic M., Dedova I. V., Tsubakihara M., Berry D. A. et al. (2003) Actin binding proteins: regulation of cytoskeletal microfilaments. Physiol. Rev. 83: 433-473

58 Brasaemle D. L., Levin D. M., Adler-Wailes D. C. and Londos C. (2000) The lipolytic stimulation of 3T3-L1 adipocytes promotes the translocation of hormone-sensitive lipase to the surfaces of lipid storage droplets. Biochim. Biophys. Acta 1483: 251-262

59 Bahler M. (2000) Are class III and class IX myosins motorized signalling molecules? Biochim. Biophys. Acta 1496: 52-59

60 Alexander M., Curtis G., Avruch J. and Goodman H. M. (1985) Insulin regulation of protein biosynthesis in differentiated 3T3 adipocytes: regulation of glyceraldehyde-3-phosphate dehydrogenase. J. Biol. Chem. 260: 11978-11985

61 Lee Y. H., Harada S., Smith R. M., Friedman R. and Jarett L. (1996) The expression of and insulin binding to cellular thyroid hormone binding protein, but not insulin degrading enzyme, is increased during 3T3-L1 adipocytes differentiation. Biochem. Biophys. Res. Commun. 222: 839-843

62 Laszlo L., Doherty F. J., Osborn N. U. and Mayer R. J. (1990) Ubiquitinated protein conjugates are specifically enriched in the lysosomal system of fibroblasts. FEBS Lett. 261: 365368

63 Guilherme A., Emoto M., Buxton J. M., Bose S., Sabini R., Theurkauf W. E. et al. (2000) Perinuclear localization and insulin responsiveness of GLUT4 requires cytoskeletal integrity in 3T3-L1 adipocytes. J. Biol. Chem. 275: 38151-38159 